\title{
Intestinal Vaginoplasty for Congenital Absence of the Vagina
}

\author{
By John R. Wesley and Arnold G. Coran \\ Ann Arbor, Michigan
}

\begin{abstract}
- Congenital absence of the vagina is rare and occurs as a result of aplasia of the Müllerian ducts $(46, X X)$ or complete androgen insensitivity syndrome (AIS-46,XY). Both syndromes are associated with normal female external genitalia and these patients are raised as females. These children are usually treated during adolescence with chronic dilatation of the shallow vaginal introitus (pressure tube technique) or by skin graft vaginoplasty (Mclndoe procedure). Neither of these procedures is entirely satisfactory, as both may lead to neovaginal stenosis, inadequate length, poor lubrication, or all three. We have recently modified the operation first described by Baldwin in which a loop of sigmoid colon or small bowel is isolated, closed at one end, and brought down on its vascular pedicle as a neovagina and anastomosed to the hymenal ring. We have performed this operation on four adolescents (mean age, 15 years) and two infants (aged 4 days and 14 months) with excellent results (mean follow-up. 7.5 years for the adolescents and 1.8 years for the infants). The advantages of a bowel segment in contrast to a skin graft are: (1) minimal likelihood of "poor take" or later contraction because a vascularized epithelial-lined tube is used; (2) patency and depth can be maintained without a mold and with minimal dilatation; (3) spontaneous mucus production matches that of the normal vagina and facilitates sexual intercourse; (4) dysparenunia frequently seen with skin grafts is avoided by the ability of the intestinal segment to withstand local trauma; and (5) the use of an intestinal segment offers the option of performing a bowel interposition vaginoplasty during infancy at the time of surgical correction of more complex associated caudal anomalies. The sigmoid colon is the best choice for interposition vaginoplasty because of size, location, and ease of preserving blood supply. Copyright $(1) 1992$ by W.B. Saunders Company
\end{abstract}

INDEX WORDS: Vaginal agenesis; Müllerian aplasia; androgen insensitivity syndrome; intestinal vaginoplasty.

Cosan ONGENITAL absence of the vagina is rare, with an incidence of 1 in 4,000 to 5,000 women. It occurs as the result of aplasia of the Müllerian ducts $(46, \mathrm{XX})$ or complete androgen insensitivity syndrome (AIS-46,XY). Both syndromes are associated with normal female external genitalia, and the patients are raised as females. Absence of the vagina is usually discovered during adolescence because of amenorrhea or failure to achieve intercourse. The most common form of treatment consists of chronic pressure dilatation of the shallow vaginal introitus by use of a graduated series of rods, the Frank method, ${ }^{1}$ or by creating a skin graft vaginoplasty around a Styrofoam mold, the McIndoe procedure. ${ }^{2}$ Neither of these procedures is entirely satisfactory, requiring what most patients regard as unpleasant instrumentation of the vagina with application of dilators or molds for several months. Both procedures may lead to neovaginal stenosis, inadequate length, poor lubrication, or all three. Even temporary noncompliance with the program of dilatation and night-time stent insertion can lead to contraction, scarring, and failure. ${ }^{3}$

We have recently modified the operation first described by Baldwin ${ }^{4}$ wherein a loop of sigmoid colon or small bowel is isolated, closed at one end, and brought down on its vascular pedicle as a new vagina and anastomosed to the introitus at the level of the hymenal ring. We have performed this operation on four adolescents (mean age, 15 years) and two infants (aged 4 days and 14 months) with excellent results.

\section{MATERIALS AND METHODS}

A summary of the diagnosis, physical findings, and operative treatment is presented in Table 1 . The gnal of the operation is to fashion a flexible and functional neovagina of bowel readily available from the gastrointestinal tract. This is most effectively accomplished using sigmoid colon as in three of our four adolescent patients, or a segment of ileum as used in the fourth. With respect to the two infants, segments of bowel were used that otherwise would have been discarded: a segment of terminal ileum attached to cecum forming the back wall of a bladder duplication in case 5 , and a cecal duplication in case 6 .

The patient is placed in the lithotomy position with her legs in stirrups or popliteal supports so that the abdomen and vaginal introitus can be prepped in one field. Broad-spectrum antibiotics are begun at the time of anesthesia induction, and a Foley catheter is placed in the bladder. The abdomen and pelvis are approached through a Pfannensteil incision. In cases of Müllerian agenesis, exploration usually shows separated remnants of uterine horns along with portions of tubes. The ovaries are usually normal in size and position. In cases of AIS (testicular feminization and its variants), the gonads are removed to prevent virilization and obviate the risk of testicular cancer. A $10-$ to $15-\mathrm{cm}$ length of sigmoid colon is isolated, preserving at least one major artery and vein at one end of the segment along with the accompanying vascular arcade (Fig 1). Depending on the local anatomy of the sigmoid loop, one end or the other is selected for the vascular pedicle and the adjacent open bowel is closed in two layers to form the vertex or cupola of the neovagina. The remaining end is left open to form the neovaginal orifice (Fig 2). It may be advantageous to rotate the isolated loop on its vascular supply $180^{\circ}$ to affect a

From the Section of Pediatric Surgery, Mott Children's Hospital, University of Michigan Medical School, Ann Arbor, MI.

Presented at the 38th Annual International Congress of the British Association of Paediatric Surgeons, Budapest, Hungary, July 24-26, 1991.

Address reprint requests to Amold G. Coran, MD, Pediatric Surgery, Mott Children's Hospital, L-2110, Ann Arbor, MI 48109-0245.

Copyright $\odot 1992$ by W.B. Saunders Company

0022-3468/92/2707-0026\$03.00/0 
Table 1. Intestinal Vaginoplasty for Congenital Absence of the Vagina

\begin{tabular}{|c|c|c|c|c|}
\hline $\begin{array}{l}\text { Case } \\
\text { No. }\end{array}$ & $\begin{array}{c}\text { Age at } \\
\text { Operation }\end{array}$ & Diagnosis & Associated Anomalies & Operation \\
\hline 1 & $17 \mathrm{yr}$ & $\begin{array}{l}\text { Congenital absence of vagina and } \\
\text { uterus; } 46, X X \text { (Rokitanski-Kuster- } \\
\text { Hanser syndrome) }\end{array}$ & $\begin{array}{l}\text { Absent left kidney; right pelvic kid- } \\
\text { ney }\end{array}$ & Sigmoid colon vaginoplasty \\
\hline 2 & $15 \mathrm{yr}$ & $\begin{array}{l}\text { Congenital absence of vagina and } \\
\text { uterus; } 46, X X \text { (Rokitanski-Kuster- } \\
\text { Hanser syndrome) }\end{array}$ & None & Sigmoid colon vaginoplasty \\
\hline 3 & $15 \mathrm{yr}$ & $\begin{array}{l}\text { Testicular feminization syndrome; } \\
46, \mathrm{XY}\end{array}$ & None & $\begin{array}{l}\text { Sigmoid colon vaginoplasty, bilateral } \\
\text { gonadectomy }\end{array}$ \\
\hline 4 & $14 \mathrm{yr}$ & $\begin{array}{l}\text { Testicular feminization syndrome; } \\
\qquad 46, X Y\end{array}$ & None & $\begin{array}{l}\text { lleovaginoplasty, bilateral gonadec- } \\
\text { tomy }\end{array}$ \\
\hline 5 & $14 \mathrm{mo}$ & $\begin{array}{l}\text { Testicular feminization syndrome; } \\
46, \mathrm{XY}\end{array}$ & $\begin{array}{l}\text { Imperforate anus; duplicated blad- } \\
\text { der }\end{array}$ & $\begin{array}{l}\text { Ileovaginoplasty; cecal augmenta- } \\
\text { tion cystoplasty; bilateral gona- } \\
\text { dectomy }\end{array}$ \\
\hline
\end{tabular}

smoother course to the vaginal orifice with less tension. A satisfactory conduit will result regardless of the direction of peristalsis. We have been able to prepare and position the sigmoid loop in each of these cases, without undue tension on the blood supply.

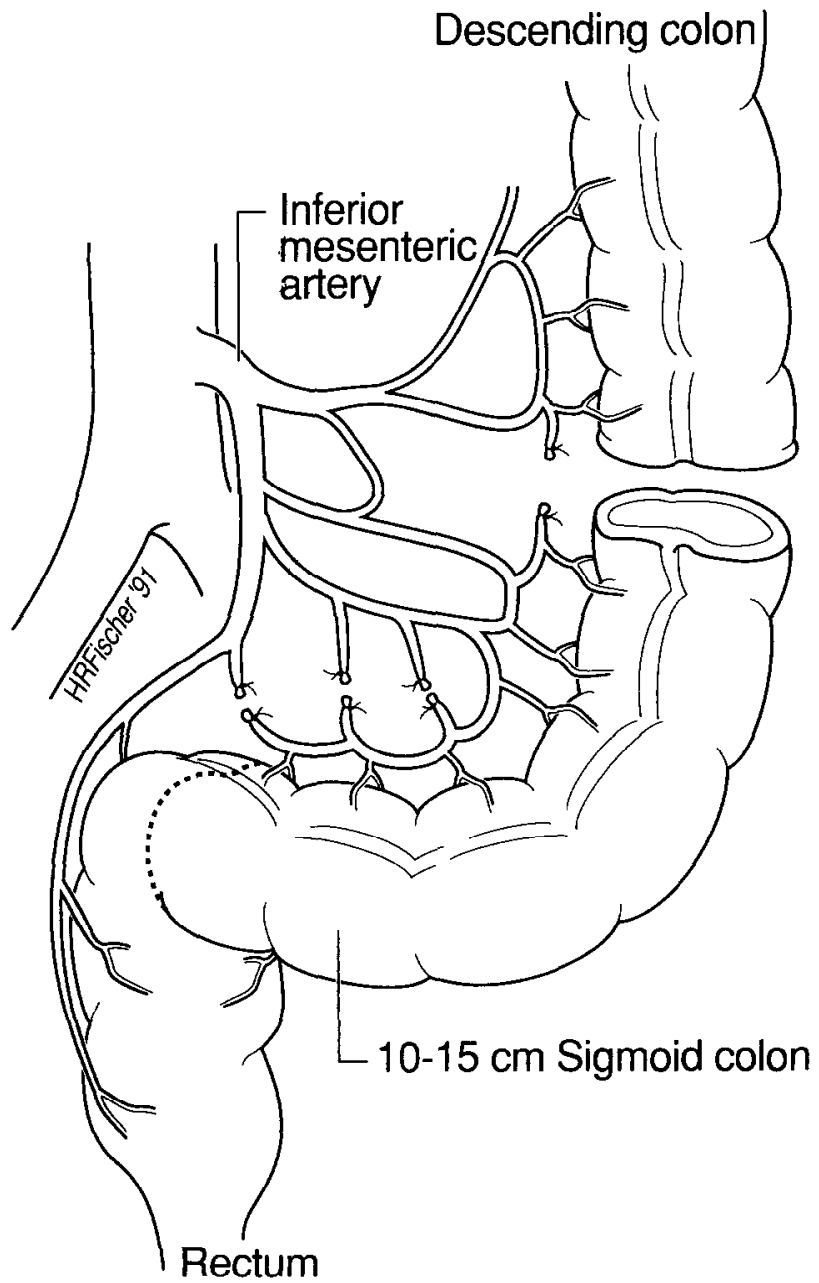

Fig 1. Isolation of 10 to $15 \mathrm{~cm}$ of sigmoid colon. The vascular arcade may be based at one end or the other. The segment-end closest to the vascular pedicle is closed in two layers to form the apex of the neovagina.
The continuity of the sigmoid colon or ileum is reestablished with a single layer anastomosis of interrupted silk sutures, and the defects in the mesentery are closed (Fig 3). The hymenal region of the vulva is then incised in a circular or cruciate fashion and the vaginal tract bluntly dissected between the bladder and rectum to the level of the peritoneal reflection in the cul-de-sac. This portion of the procedure can also be done from above downward; specifically, a Hegar dilator can be pushed upward in the rudimentary introitus, and the bulging peritoneum in the cul-de-sac cut down on

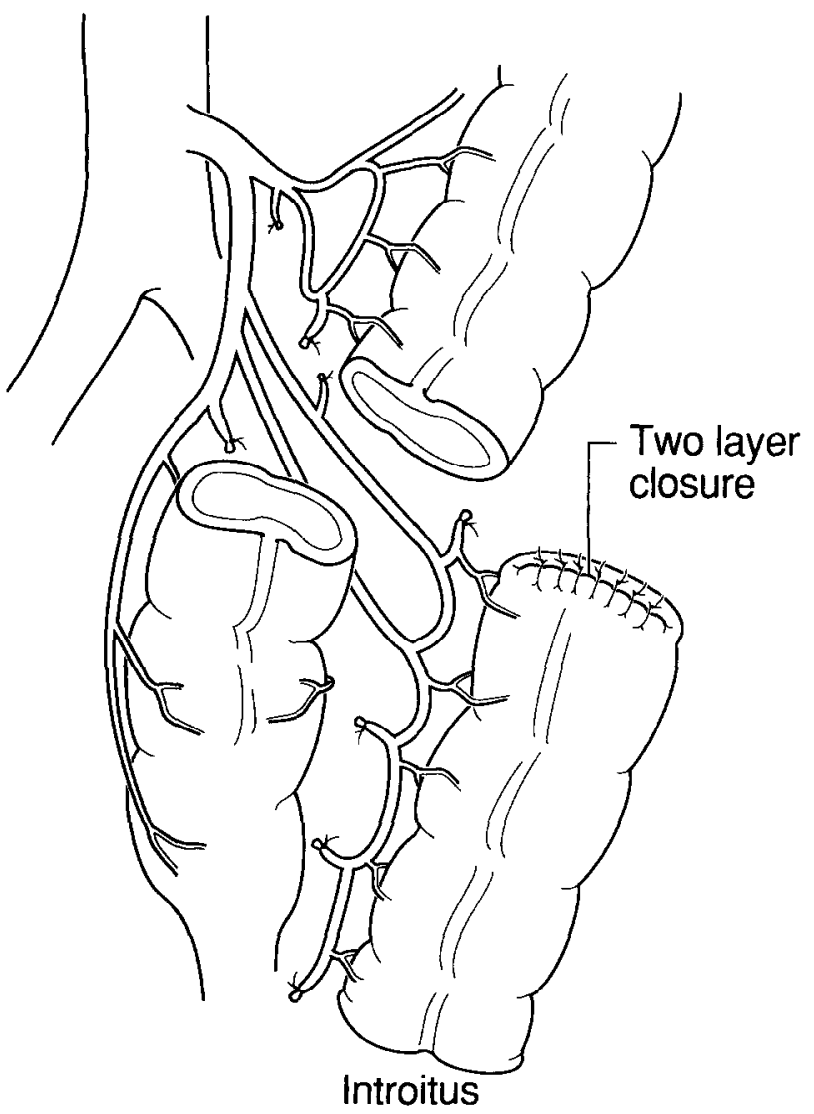

Fig 2. The bowel segment has been positioned to anastomose to the hymenal ring. Care is taken to avoid tension on the vascular pedicle. 


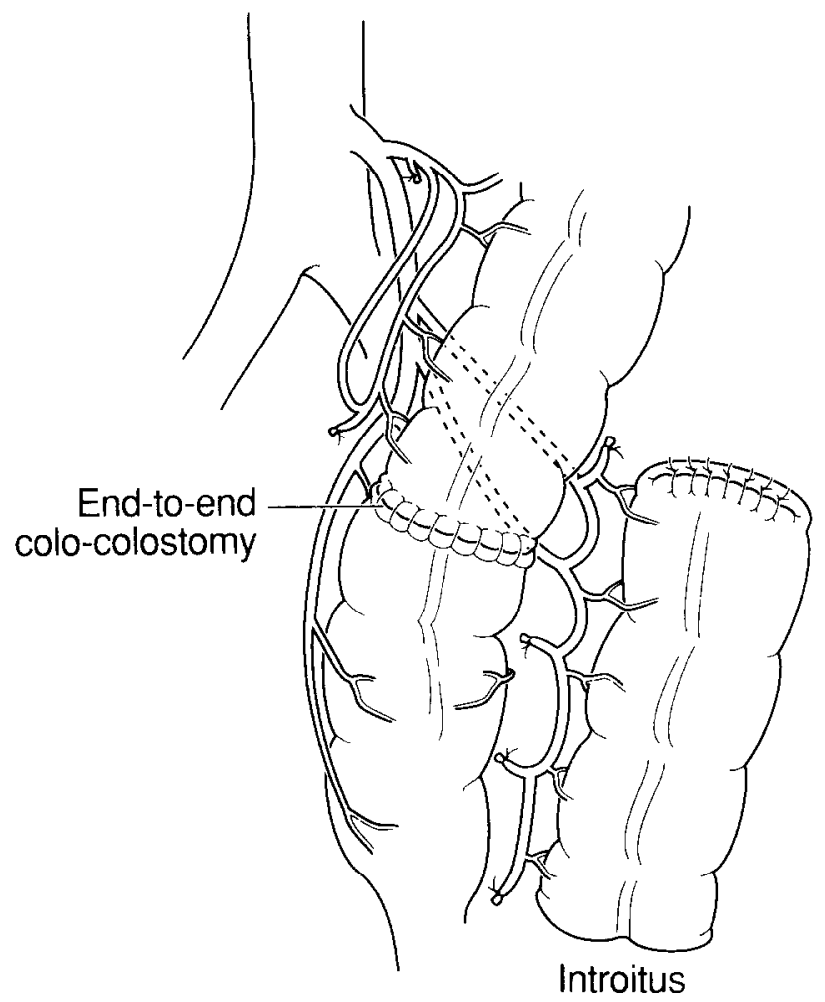

Fig 3. Colocolostomy has been completed and the distal end of the colonic segment has been anastomosed to the opened rudimentary vaginal pit.

from above. The peritoneum is incised and the open sigmoid loop pulled down by means of stay sutures. The position of the bowel is checked with particular attention given to its blood supply, and to ensure that it is not angulated or under appreciable tension. If necessary, the open end of the sigmoid loop is spatulated along the antimesenteric border and a generous single-layer anastomosis performed in the hymenal regional with absorbable suture.

Remnants of the uterus should be excised. Available peritoneum of the cul-de-sac and broad ligaments are used to extraperitonealize the transplanted segment of the sigmoid colon. Meticulous hemostasis should be maintained throughout the procedure; the dissected vaginal tract is usually dry. If necessary, one or two small Jackson-Pratt drains can be left next to the transplanted segment of bowel to prevent hematoma formation. A loose vaseline gauze pack is placed in the neo-vagina to effect a snug approximation of bowel to the surrounding tissues (Fig 4).

\section{RESULTS}

The results are outlined in Table 2 . There were no operative complications in any of the six intestinal vaginoplasties. Experience with the first three patients (cases 1 to 3 , Tables 1 and 2) has been particularly gratifying. Each patient was taught, and easily adapted to, the neovagina dilatation with a Hegar dilator ranging in size from 20 to 26 . This might more appropriately be termed a calibration rather than a dilatation in that the neointroitus and colonvagina remained generous and supple in each patient. Weekly calibration was continued for 6 months to 1 year, until sexual intercourse made calibration no longer necessary. All three patients report satisfactory and satisfying sexual intercourse; the first two are married and the third has a boyfriend. None of the three require lubrication, and only one reported occasional spotting from mucus production. The fifth patient who underwent an ileovaginoplasty was last seen at age $17,2 \frac{1}{2}$ years after her procedure, at which time she had a tight vaginal vault. She had been instructed in daily dilatation with a no. 20 Hegar dilator. She was not sexually active. Compliance with the dilatation program was poor, and she has been since lost to further follow-up.

The first of the two infants was born with an imperforate anus and initially underwent an ileostomy and mucus fistula, with an 8-cm segment of ileum coming off of a foreshortened colon, consisting of cecum attached to the dome of a neurogenic bladder duplication. She underwent a cecal augmentation cystoplasty at age 14 months, at which time the residual ileum, which had been part of the mucus fistula, was brought down to form a neovagina. She is now 5 years old and undergoes periodic dilatation of the neovagina with a no. $6 \mathrm{Hcgar}$ dilator in the office. The vaginal orifice is tight and she will probably require enlargement of the introitus when she reaches adolescence.

The second infant (case 6) was born with multiple congenital anomalies, including exstrophy of the bladder, omphalocele, and a cecal duplication. The latter, at the time of closure of the omphalocele and exstrophy, could be easily mobilized and brought down to fashion a neo-vagina. This seemed to be a

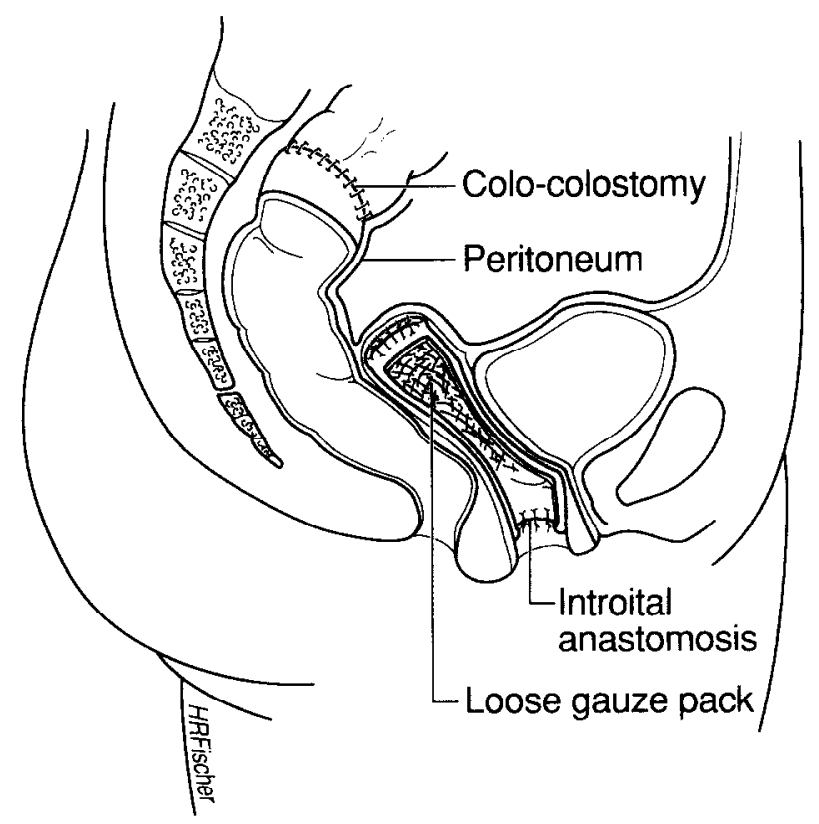

Fig 4. The completed vaginoplasty has been loosely packed with vaseline gauze and the peritoneum closed above the transposed bowel. 
Table 2. Results and Follow-Up of Intestinal Vaginoplasty for Congenital Absence of the Vagina

\begin{tabular}{|c|c|c|c|c|c|}
\hline \multirow{2}{*}{$\begin{array}{l}\text { Case } \\
\text { No. }\end{array}$} & \multirow[b]{2}{*}{ Operation } & \multirow{2}{*}{$\begin{array}{l}\text { Duration of } \\
\text { Follow-Up }\end{array}$} & \multicolumn{2}{|r|}{ Results } & \multirow{2}{*}{$\begin{array}{c}\text { Pertinent } \\
\text { Postoperative History }\end{array}$} \\
\hline & & & Anatomic & Physiological & \\
\hline 1 & Sigmoid colon vaginoplasty & $6 \mathrm{yr}$ & Excellent & Married, normal sexual intercourse & $\begin{array}{l}\text { Weekly dilatation for } 6 \text { mo, then reg- } \\
\text { ular intercourse; needs no lubrica- } \\
\text { tion }\end{array}$ \\
\hline 2 & Sigmoid colon vaginoplasty & $12 \mathrm{yr}$ & Excellent & Married, normal sexual intercourse & $\begin{array}{l}\text { Weekly dilatation for first year, then } \\
\text { sporadic; needs no lubrication; } \\
\text { occasional spotting }\end{array}$ \\
\hline 3 & Sigmoid colon vaginoplasty & $11 \mathrm{yr}$ & Excellent & Excellent, normal sexual intercourse & $\begin{array}{l}\text { Weekly dilatation for first year: } \\
\text { needs no lubrication }\end{array}$ \\
\hline 4 & Ileovaginoplasty & $2.5 \mathrm{yr}$ & Good & $\begin{array}{l}\text { Unknown, unmarried, no sexual in- } \\
\text { tercourse }\end{array}$ & \\
\hline 5 & $\begin{array}{l}\text { Ileovaginoplasty; cecal augmenta- } \\
\text { tion cystoplasty }\end{array}$ & $4 \mathrm{yr}$ & $\begin{array}{l}\text { Good, narrow } \\
\text { introitus }\end{array}$ & NA & Requires periodic dilatation \\
\hline 6 & $\begin{array}{l}\text { Colon vaginoplasty (using cecal du- } \\
\text { plication) }\end{array}$ & $5 \mathrm{mo}$ & Excellent & NA & $\begin{array}{l}\text { Died at home, age } 16 \mathrm{mo} \text {, suspected } \\
\text { pulmonary embolus }\end{array}$ \\
\hline
\end{tabular}

very appropriate use for the segment of duplicated bowel rather than to resect and discard it.

She died at age 16 months of complications of home parenteral nutrition.

\section{DISCUSSION}

Congenital absence of the vagina is most commonly caused by Müllerian aplasia, and is frequently called by the eponym Rokitansky-Küster-Hauser syndrome. Müllerian aplasia is usually accompanied by a rudimentary uterus in the form of bilateral and noncanaliculated muscular buds, normal tubes and ovaries, normal female secondary sex characteristics, and otherwise normal endocrine and cytogenic evaluations. The differential diagnosis of absence of the vagina in an otherwise normal appearing female includes partial absence of the vagina (usually the lower third) and testicular feminization, or the AIS. The latter may be diagnosed during infancy due to the high incidence of bilateral inguinal hernias. The vagina in these patients will be abnormally shallow or absent all together.

Because of the high incidence (up to $50 \%$ ) of isolated urinary tract anomalies in patients with congenital absence of the vagina, such as absence of one kidney, horseshoe kidney, pelvic kidney, or duplicated collecting systems, intravenous pyelography or a computed axial tomography scan with intravenous contrast should be done preoperatively. ${ }^{3}$ Skeletal malformations are common (up to 12\%) and spinal films may show vertebral anomalies. ${ }^{5}$ However, the most important aspect of the preoperative evaluation is the establishment of a close doctor-patient relationship such that the surgeon is assured that the patient will cooperate with the use of vaginal dilators and return regularly for follow-up evaluation. ${ }^{3}$

The Frank technique of nonoperative forceful dilatation of the vaginal introitus is most successful in highly motivated individuals with a vaginal dimple of 3 or $4 \mathrm{~cm} .1,3,6$

The McIndoe technique and its variations has been widely applied..$^{5,7,8}$ Good results can be obtained provided that the graft is complete. Its successful function and result is dependent on a mold being worn for many months in order to overcome the contractile phase of the healing skin graft.

Lubrication is required for satisfactory sexual intercourse and dysparenia has been a frequent complaint. There are now seven reported cases of squamous cell carcinoma arising in split-thickness skin graft vaginoplasties, ${ }^{9,10}$ and two reported cases of adenocarcinoma in segmental bowel vaginoplasties. ${ }^{11}$

Our experience and that of others ${ }^{11}$ has been that the sigmoid colon serves as an extraordinarily effective substitute for the vaginal canal. Obtaining adequate length is no problem, and there is no tendency toward contraction, narrowing, or stenosis provided that the bowel segment has an adequate blood supply, and that the anastomosis to the hymenal region is generous. Wearing a stent is unnecessary and dilatations, if needed at all, are temporary, infrequent (we recommend once weekly), and well tolerated.

The thick wall of the colon tolerates trauma with less reaction and bleeding than does small bowel or split-thickness skin graft. Bleeding may be intermittent or bothersome during the first month or two, but thereafter rarely occurs. Initially exuberant mucus production by the sigmoid neovagina gradually tapers off over 1 to 2 months and generally has not been a problem..${ }^{11}$ The mucosa atrophies to a mild degree in its new position, and once-a-week douches are helpful to prevent collections of inspissated mucus. Moreover, mucus production is sufficient to keep the neovagina moist, and lubrication before intercourse is unnecessary.

The advantages of a bowel segment vaginoplasty 
over prolonged forceful dilation of a shallow rudimentary vaginal pit, or split-thickness skin graft inserted over a mold are: (1) minimal likelihood of "poor take" or later contraction because a vascularized epithelial-line tube is used; (2) initial length is no problem and patency and depth can be maintained without a mold and with minimal dilatation; (3) spontaneous mucus production matches that of the normal vagina and facilitates comfortable sexual intercourse; (4) dyspareunia, frequently experienced with skin grafts, is avoided by the greater resistance of the sigmoid segment to local trauma; (5) the opera- tion is straightforward, safe, and unaccompanied by the scarring associated with split thickness skin grafts; and (6) the use of an intestinal segment offers the options of performing bowel interposition vaginoplasty during infancy at the time of surgical correction of more complex associated caudal anomalies. The sigmoid colon is the best choice for interposition vaginoplasty because of size, location, and ease of preserving blood supply. Minimal long-term care is required, although surveillance must be maintained at regular intervals (every 6 months) to watch for adenocarcinoma in the transplanted bowel segment.

\section{REFERENCES}

1. Frank RT: The formation of an artificial vagina without operation. Am J Obstet Gynecol 35:1053-1055, 1938

2. McIndoe A: The treatment of congenital absence and obliterative conditions of the vagina. Br J Plast Surg 2:254-267, 1950

3. Capraro VJ, Gallego MB: Vaginal agenesis. Am J Obstet Gynecol 124:98-107, 1976

4. Baldwin JF: The formation of an artificial vagina by intestinal transplantation. Ann Surg 40:398-403, 1904

5. Wiser WI, Bates GW: Management of agenesis of the vagina Surg Gynecol Obstet 159:108-112, 1984

6. Bryan AL. Nigro JA, Counseller VS: One hundred cases of congenital absence of the vagina. Surg Gynecol Obstet 88:79-86, 1949

7. Khanna S, Khanna MN: Congenital absence of vagina: An analysis of 18 cases corrected by the McIndoe operation using a condom mould. Int Surg 67:345-346, 1982

8. Buss JG, Lee RA: McIndoe procedure for vaginal agenesis: Results and complications. Mayo Clin Proc 64:758-761, 1989

9. Hopkins MP, Morley GW: Squamous cell carcinnma of the neovagina. Obstet Gynecol 69:525-527, 1987

10. Baltzer J, Zander J: Case report: Primary squamous cell carcinoma of the neovagina. Gynecol Oncol 35:99-103, 1989

11. Pratt JH, Smith GR: Vaginal reconstruction with a sigmoid loop. Am J Obstet Gynecol 96:31-40, 1966 